Article

\title{
Exploring the Experienced Impact of Studentification on Ageing-in-Place
}

\author{
Debbie Lager ${ }^{1,2, *}$ and Bettina van Hoven ${ }^{3}$ \\ ${ }^{1}$ School of Social Studies, Hanze University of Applied Sciences, 9747 AS Groningen, The Netherlands; \\ E-Mail: d.r.lager@pl.hanze.nl \\ 2 Department of Cultural Geography, Faculty of Spatial Sciences, University of Groningen, 9700 AV Groningen, \\ The Netherlands \\ ${ }^{3}$ Faculty of Spatial Sciences, University of Groningen, 9700 AV Groningen, The Netherlands; E-Mail: b.van.hoven@rug.nl \\ * Corresponding author
}

Submitted: 23 December 2018 | Accepted: 5 March 2019 | Published: 18 June 2019

\begin{abstract}
In this qualitative study we explore the experienced impact of studentification on ageing-in-place (i.e., ageing in one's own home and neighbourhood for as long as possible). Studentification, which refers to concentrations of students in residential neighbourhoods, has been associated with deteriorating community cohesion by several authors. This can negatively affect existing neighbourhood support structures. In examining this topic, we draw on in-depth interviews with 23 independently living older adults $(65+)$ which were conducted in a studentified urban neighbourhood in the Netherlands. Our results show how the influx of students in the neighbourhood negatively affected older adults' feelings of residential comfort. In spite of this, none of the participants expressed the desire to move; they experienced a sense of familiarity and valued the proximity of shops, public transport and health services, which allowed them to live independently. To retain a sense of residential mastery, our participants dealt with negative impacts of studentification, at least in part, by drawing on accommodative coping strategies that weigh in broader experiences of physical and social neighbourhood change. In doing so, they rationalised and reassessed their negative experiences resulting from studentification. We discuss the implications of our findings for the development of age-friendly neighbourhoods.
\end{abstract}

\section{Keywords}

ageing-in-place; age-friendly neighbourhoods; qualitative research; studentification; The Netherlands; urban ageing

\section{Issue}

This article is part of the issue "The City, Aging and Urban Planning", edited by Matthias Drilling (University of Applied Sciences and Arts Northwestern Switzerland) and Fabian Neuhaus (University of Calgary, Canada).

(C) 2019 by the authors; licensee Cogitatio (Lisbon, Portugal). This article is licensed under a Creative Commons Attribution 4.0 International License (CC BY).

\section{Introduction}

The proportion of the older population $(65+)$ in OECD countries is rapidly increasing. Comprising $18 \%$ of the total population in 2010, it is projected that by 2050 one in four people will be aged 65 or above (OECD, 2015). Dealing with the increased costs of population ageing, many western governments have moved away from institutional care to ageing-in-place. As a result, older people are to remain living in their own homes and neighbourhoods for as long as possible. It is assumed that older adults benefit from informal care and support of family, friends and neighbours and the sense of independence and well-being they derive from ageing in familiar surroundings. However, these policy assumptions do not always correspond with the lived reality of those ageing in place (Golant, 2015; Lager, Van Hoven, \& Huigen, 2013). Research suggests that older people can experience loneliness, obstacles to building social capital and a sense of exclusion from their locality (e.g., Buffel et al., 2012; Lager et al., 2015).

In 2006, to help develop supportive urban communities for older citizens, the World Health Organization (WHO) initiated the "Global Age-Friendly Cities" project. 
In this project, cities around the world that were interested in supporting healthy ageing by becoming more age-friendly were brought together (Government of Canada, 2016). In the WHO's (2007) published guide, key characteristics of an age-friendly city were identified in terms of the built environment, social inclusion and service provision (see Figure 1).

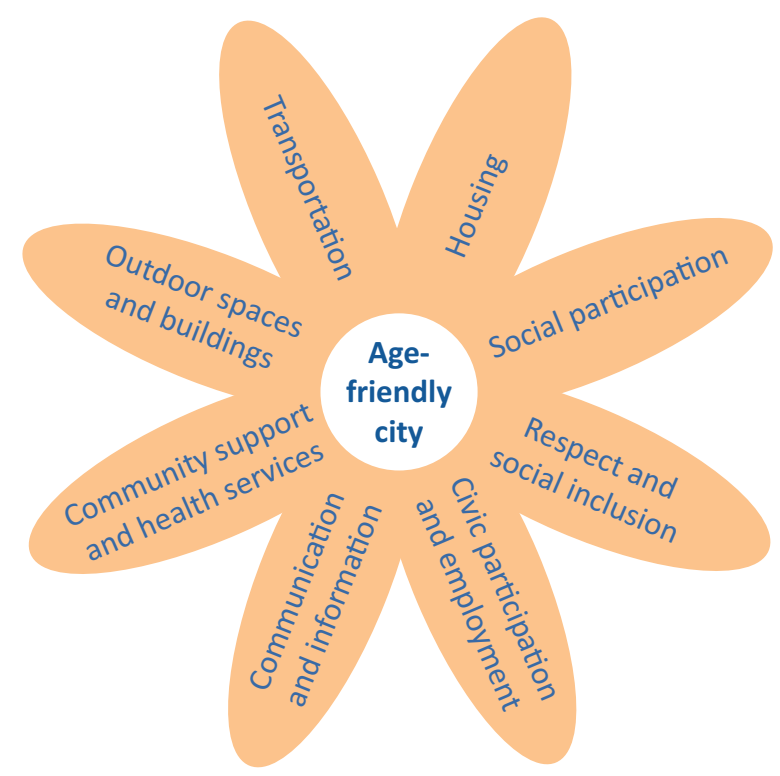

Figure 1. The age-friendly city model according to WHO (2007).

This guide has become one of the most frequently used tools to assess the age-friendliness of cities and communities across the world (Buffel \& Phillipson, 2018). Buffel and Phillipson (2018, p. 179) point out that "age-friendly activity has developed in the absence of a critical perspective on the way in which urban societies are changing". One of these issues concerns urban regeneration schemes, which can bring about economic and social inequalities, with "gentrified neighbourhoods at one end and areas of concentrated poverty at the other" (Buffel \& Phillipson, 2018, p. 179). There is thus a need for greater knowledge of particular challenges for developing age-friendly initiatives, and for older adults to experience age-friendliness, in communities and neighbourhoods to feed into the further development of an agefriendly agenda.

It is in this context that we explore how older adults experience studentification and what the impacts are on ageing-in-place. Studentification concerns concentrations of students in areas within university towns and cities as a result of student housing in multiple occupation (HMOs) and/or purpose-built student accommodation (PBSA; Sage, Smith, \& Hubbard, 2013; Smith, 2006). These include residential properties which are shared by more than one household and usually have common areas (e.g., shared bathroom and kitchen), either originally designed for occupation by one family (HMOs) or designed for student accommodation (PBSA). The body of literature concerning the studentification of neighbourhoods has emphasised the negative social and cultural effects of this transient population on local communities, specifically a sense of a deteriorating community cohesion among non-student residents (e.g., Hubbard, 2008; Sage et al., 2012, 2013; Smith, 2008). Sage et al. (2013, p. 2636) argue that studentification might produce "deep social divides along age cleavages" that could even result in an "age-divided city". For the older population living in studentified neighbourhoods, such a scenario might impair the perceived quality of life and neighbourhood support structures (Allinson, 2006; Sage et al., 2012). So far, to the best of our knowledge, studentification has not been discussed within the context of ageing-in-place. It seems to be a timely issue for university towns and cities, as they are faced with accommodating the various and, one might argue, opposing needs of both groups.

The idea for this article arose from our broader study on the subjective dimensions of ageing-in-place (see Lager et al., 2013, 2015, 2016). For this explorative study we conducted in-depth interviews with independently living older adults $(65+)$ in three urban neighbourhoods in the city of Groningen, the Netherlands. During the time of the fieldwork in one of these neighbourhoods there was discontent and protest among the local residents regarding the studentification of their neighbourhood. In this article, we investigate how older residents of this particular neighbourhood experience neighbourhood changes, and particularly the impact of studentification as a significant part of this. First, we discuss the relevance of the neighbourhood for ageing-in-place. We then introduce the research context and approach. Next, the findings reveal how the studentification of the neighbourhood is tied up with experiencing neighbourhood decline. In the discussion we focus on the implications of our findings for ageing-in-place policy and the development of age-friendly neighbourhoods.

\section{Ageing-in-Place in Urban Neighbourhoods and Studentification}

Previous studies have noted several implications of studentification on the physical and social context of a neighbourhood. In order to relate this to its impact on older adults and ageing-in-place we first outline the role of the neighbourhood for older adults.

The neighbourhood, as a physical and social place of ageing, is argued to be more important for the well-being of older adults than for younger and employed people (Buffel et al., 2012). Generally, older adults tend to spend more time in their locality than their younger and employed counterparts (Buffel et al., 2012). To an extent, this has to do with retirement, which marks a shift from the workplace to the residential environment (Hagestad \& Uhlenberg, 2005). Decreasing physical mobility and diminishing health can limit the time and energy available to engage in activities which are further from home 
(Droogleever Fortuijn et al., 2006). As older adults spend increasing amounts of time in their direct environment, the neighbourhood as an experiential setting gains in importance (Golant, 2015). Local social contacts are found to be important to older adults' well-being in terms of experiencing sociability in the public places of the neighbourhood (e.g., Gardner, 2011; Lager et. al. 2015; Smith, 2009). With diminishing institutionalised resources and older adults' diminishing levels of independence, these local social contacts can become particularly important in securing social, emotional and instrumental support (Buffel et al., 2012).

Social embeddedness emerges from extensive periods of living in a neighbourhood (Gardner, 2011). Residential stability may result in a strong place attachment to the locality, an aspect that is of particular importance in older adults' well-being. Place attachment stems from a person's physical, social and autobiographical "insideness" (Rowles, 1983). This "insideness", or familiarity with a place, results from spatial routines and habits (physical insideness), integration in local social networks (social insideness) and the remembrance of events that develops through length of residence (autobiographical insideness; Rowles, 1983). Familiarity with the materiality of a neighbourhood can be beneficial in carrying out activities of daily living, such as grocery shopping, when physical and/or cognitive functions decrease in later life. This, in turn, can confer a sense of safety, control and independence (Buffel et al., 2012; Wiles, Leibing, Guberman, Reeve, \& Allen, 2012). Place attachment has a functional dimension as well as an affective dimension. Experiences and feelings about the home and the neighbourhood can produce an emotional attachment to these places. This attachment can serve as a means to keep memories throughout the life course alive, thereby contributing to maintaining a sense of continuity of the self (Rubinstein \& Parmelee, 1992).

Older adults' subjective experiences of their residential environment are important for understanding what matters most for ageing-in-place well (Golant, 2015). As Golant (2015, p. 13) notes, "the objectively defined environments portrayed by the experts do not necessarily have the same functional relevance for older people". To categorise older adults' residential emotional experiences, he introduced the model of residential normalcy. Here, a distinction is made between 'residential comfort' (the extent to which they experience pleasurable, hasslefree and memorable feelings) and 'residential mastery' (the extent to which they feel they are competent and in control). A positive valuation of both categories contributes to experiencing overall favourable residential experiences. The neighbourhood environment can magnify these experiences.

Urban neighbourhoods can create advantages and pose challenges with regard to older adults' well-being (Phillipson, 2014). On the one hand, urban environments can "produce advantages for older people in respect of access to specialized medical services, provision of cul- tural and leisure facilities, and necessities for daily living" (Phillipson, 2014, p. 1). This variation can bring about a range of positive emotions, such as relaxation, invigoration and excitement (Negrini, 2015). On the other hand, research on ageing in changing and deprived neighbourhoods has shown how urban environments can confer environmental stress and can contribute to older adults' social exclusion (e.g., Buffel, Phillipson, \& Scharf, 2013; Smith, 2009; Van der Meer, Droogleever Fortuijn, \& Thissen, 2008). In particular, this can jeopardise the well-being of older adults who lack the financial means to venture or move beyond the neighbourhood and thereby get stuck in these places (Phillipson, 2007).

It should be noted that the extent to which older adults experience their neighbourhood positively or negatively also relates to their coping repertoires (Golant, 2015). People may use psychological strategies (accommodative coping) to deal with obstacles and restraints in their residential environment, for instance by rationalising or reappraising their situation. They may also come into action (assimilative coping) and will try to make their problems go away, for instance, by modifying their activities or moving to another residential environment.

Based on the literature on studentification, it can be argued that, generally speaking, it does not positively contribute to older adults' residential experiences. In a study on a studentified neighbourhood in the UK, Sage et al. (2012, p. 1070) noted that, for established residents, "intergenerational differences in social expectations" can result in negatively experienced interactions with students. In general, the student population is young, seasonal and transient (Smith, 2006). As they only reside in an area during term-time, and for a maximum of about three years, they may fail to become involved in the community and may have less commitment to upholding the quality of the local environment (Hubbard, 2008; Smith, 2006). Smith (2006, p. 18) noted that the transient character of the student population and the negative effects of their presence, such as noisenuisance and anti-social behaviour, can lead to "a gradually self-reinforcing unpopularity of the area for families" and, as a consequence, the character of the community changes. This can negatively impact on the older residents living in these places as studentification will then affect existing neighbourhood support structures. People need to know each other in order to become aware of when an older person is in need of support (Droogleever Fortuijn et al., 2006) and this may not happen due to the transient nature of students' residence in the neighbourhood.

Previous studies have found that students are less concerned with (or not in charge of) the maintenance of the area surrounding their residence, leading to littering and sidewalks that are overgrown with weeds from neglected gardens (Hubbard, 2008; Sage et al., 2012). Studentification has also been associated with traffic and parking issues, such as a shortage of off-street parking, causing congested streets. This may jeopardise the ac- 
cessibility of the public spaces of the neighbourhood for those with visual and/or mobility impairments (Hubbard, 2008; Sage et al., 2012). Nevertheless, studentification can have a range of positive social and cultural impacts on neighbourhoods and for older people residing in these neighbourhoods. For instance, the presence of students can bring a sense of liveliness to the community (Allinson, 2006).

\section{Research Context and Approach}

In this article, we draw on in-depth interviews with 23 older adults in Selwerd (see Figure 2), a neighbourhood in the city of Groningen, that were conducted in 2010. Groningen (202,747 inhabitants; Onderzoek en Statistiek Groningen, 2018) can be considered a typical European city in terms of its high population density and its radioconcentric spatial structure. Groningen houses two institutes of higher education and attracts many students from the region, which results in a relatively young population compared to other Dutch cities.

In the context of Groningen, the neighbourhood of Selwerd is particularly appropriate for exploring how studentification can impact on ageing-in-place. Selwerd, a post-war neighbourhood built in the 1960s, is home to many residents who have lived there for several decades. Currently, $16 \%$ of Selwerd's residents are aged 65 and above, a slightly higher proportion than the municipal- ity's average of 13\% (Onderzoek en Statistiek Groningen, 2018). Selwerd was designated as an important location for student housing in the 1960s and three blocks of student flats were built there (see Figure 3 ). The neighbourhood is situated between the city centre and the Zernike University Campus and it only takes 5 to 10 minutes to reach either by bicycle, making it an attractive residential location for students. Currently, $13 \%$ of the neighbourhood's population consists of students. For the older population, the variety of shops present in Selwerd that cater for residents' everyday needs, as well as an indoor shopping centre in an adjacent neighbourhood and convenient access to public transport, make the neighbourhood a suitable place to age in place.

Since the year 2000, the neighbourhood has been in somewhat of a decline and became less attractive for families (Gemeente Groningen, 2010). As a consequence, housing prices in Selwerd stagnated which made it profitable for letting agencies and students' parents to buy and rent terraced homes and apartments (Gemeente Groningen, 2010). As a result, the number of students in HMOs in Selwerd increased, which led to unrest among the established residents who feared this process would further undermine social cohesion in Selwerd. In 2009, the neighbourhood council called for a student lock on this neighbourhood, which was adopted by the executive board of the municipal council in the same year. This meant that no new permits for HMOs were issued.

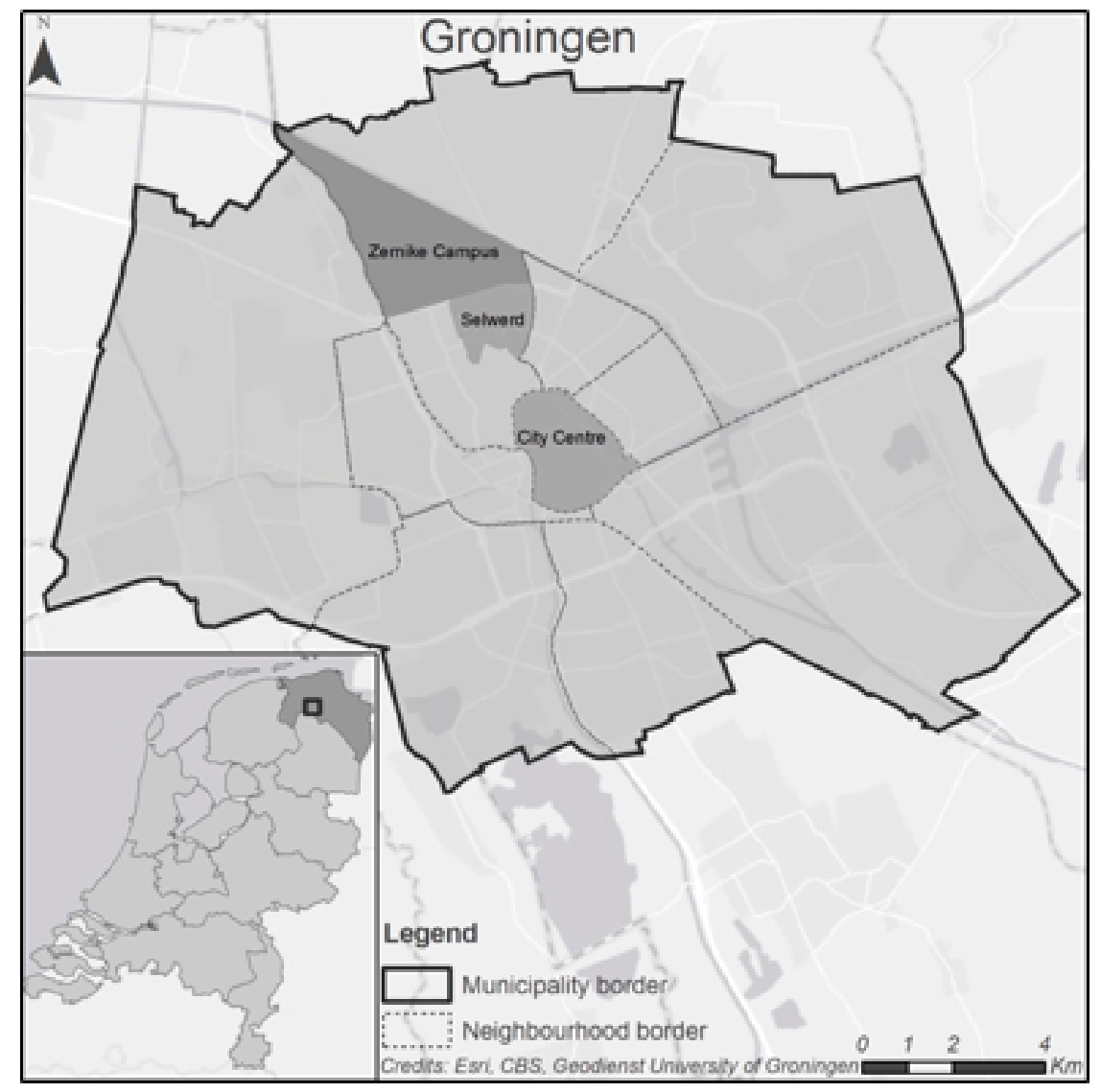

Figure 2. The neighbourhood of Selwerd, located between the Zernike Campus and Groningen city centre. 


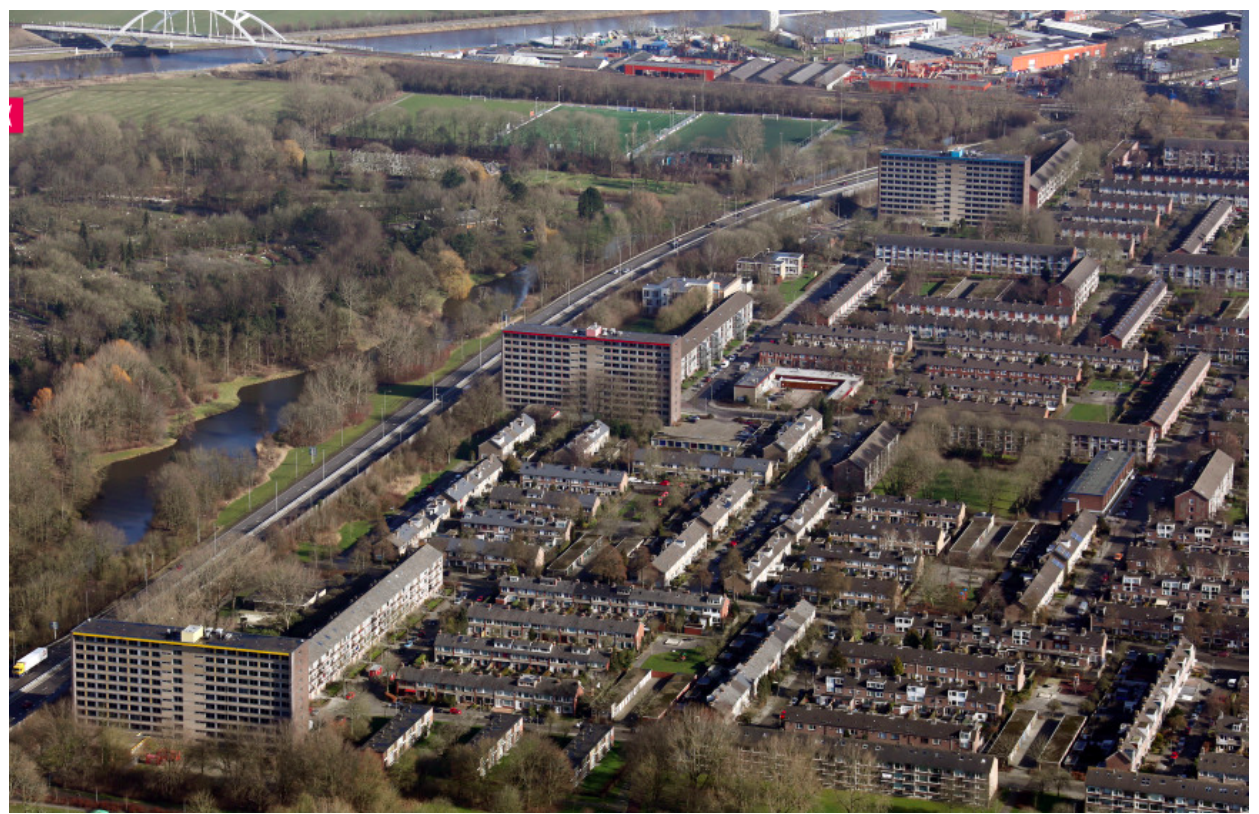

Figure 3. Selwerd seen from above, with three student flats located on the left. Retrieved from staatingroningen.nl

In 2013, a neighbourhood renewal programme commenced in Selwerd and the student lock was abolished in 2015.

In this research, five post-graduate student researchers (including the first author of this article) recruited participants through activities in Selwerd's community centre, door-to-door recruitment, and snowball sampling. The final group of participants comprises a self-selected sample where the only criterion for inclusion was that participants were older than 65 years. All the participants were white and had Dutch nationality (see Table 1 for their main characteristics). They were

Table 1. Characteristics of the participants.

23 participants

\section{Sex}

Women

12 participants

Men

11 participants

Age

65-79

13 participants

$80+$

10 participants

Marital status

Widowed

Married

13 participants

Single/divorced

8 participants

2 participants

Type of housing

Senior apartment

Single-family home

18 participants

5 participants

\section{Years of living in Selwerd}

1-9

10-39

40-47

5 participants

6 participants

12 participants informed about the research through a letter of introduction that they received in their letterbox. At the start of the interview, the researchers explained the interview procedure, how research outcomes would be disseminated, and obtained informed consent. Participants' names and any other information that could be traced were changed to ensure anonymity.

In-depth semi-structured interviews were conducted with all participants in their own homes. The interview questions focused on experiences, feelings and memories of participants' current residence, daily life in the neighbourhood, local social contacts and neighbourhood change. We did not ask specific questions about studentification. Transcripts were coded by the authors of this article, using qualitative data analysis software (NVivo8) applying thematic analysis (see Kitchin \& Tate, 2000). In doing so, we were able to extract information from interview transcripts by themes pre-identified in the interview scheme. These themes originate from the theoretical framework and comprise our theoretical codes. In addition, new themes emerged from further open coding during analysis, primarily those regarding the relationships and experiences of older adults with students in the neighbourhood. The analysis continually moves between empirical data and theory as new findings are contextualised and interpreted using theory. This approach to coding draws on grounded theory but is more pre-structured as a result of the theoretically-informed interview-scheme which is leading in the analysis. The interaction between empirical data and theory is also called "analytical generalisation" (Baxter, 2016).

\section{Ageing-in-Place in a Neighbourhood in Transition}

During the analysis, it emerged that the participants felt conflicted about the suitability of the neighbourhood for 
ageing-in-place. On the one hand, the majority of the participants were content with their residence, the location of their residence in relation to the shopping centre and access to public transport and health services. Yet, our participants' stories also highlight how their residential comfort was negatively impacted by the studentification of the neighbourhood. The sections below are structured around two key themes that resulted from the analysis of our data. Section 4.1 focuses on the experienced impact of studentification on participants' residential comfort. Section 4.2 focuses on the accommodative coping strategies participants used to deal with negative residential experiences resulting from studentification.

\subsection{Experiencing Neighbourhood Change}

As we indicated in Section 3, three blocks of student flats were built in Selwerd in the 1960s. The participants who moved to Selwerd in the 1960s were thus already acquainted with students being present in the neighbourhood. However, in recent years they noticed how the terraced homes, originally designed for families, were purchased by parents who then sublet them to their studying children and their friends:

A lot has changed. There are more students. It's not like they should not get a place to stay, but they are buying normal houses; low-rise properties. In some of these houses there are up to six students. Well, you should see their curtains [not very proper] and that does not make me very happy. (Claire, female, 81)

This quote furthermore demonstrates how the increase of HMOs negatively affected participants' feelings of residential comfort (Golant, 2015). Participants complained about littering, noise, poorly maintained gardens, kerbs overgrown by weeds and parking issues, which mirrors the results of studies on the experienced impact of studentification on local communities (e.g., Hubbard, 2008; Sage et al., 2012; Smith, 2006). Some participants indicated that students' inconsiderate parking of their bicycles (a Dutch phenomenon) and kerbs overgrown by weeds from student houses' neglected gardens, jeopardised the accessibility of the streets when they walk around the neighbourhood:

The neighbourhood is deteriorating and that's because of students. They park their bicycles everywhere. They have like six or seven bicycles and you just fall over them. (Sophie, female, 84)

Especially for the participants who have resided in Selwerd for several decades, the deteriorating quality of the local environment negatively affected their emotional attachment to the neighbourhood. This is exemplified in the following quote by Ellen (female, 76). When she was asked how the increase of students in Selwerd affected her, she replied:
Last week we [Ellen and her husband] walked through our old street, but I do not care anymore. It used to be so tidy, but now you can barely walk across the sidewalk. They don't maintain their gardens. It does not mean anything to us anymore. We used to live there with great joy for thirty years and now it does not mean a thing to us.

In spite of this waning emotional attachment, none of the participants expressed the desire to move to another neighbourhood. The majority of the participants indicated that they felt at home in Selwerd. When asked why they felt at home, a common denominator turned out to be a sense of familiarity (or related fear of the unknown; see also Smith, 2009) and the proximity of facilities and services, which enabled them to live independently. Those who lived in the neighbourhood for several decades also indicated they felt at home because of their social embeddedness in the neighbourhood; they were greeted by other older residents and had friends and acquaintances living in their proximity:

We want to stay in this neighbourhood, because of the shopping centre, the bus, the train, our GP, the pharmacy. If we were to move, we would have to change a lot. And our ex-colleagues and friends live in this neighbourhood. We don't see them that often, but we're there for each other when we need each other's help. (Kees, male, 78)

Golant $(2015$, p. 106) pointed out that "older people's desire to age in place acts as a powerful deterrent to moving". As we will discuss in the next paragraph, the participants dealt with this residential discomfort, at least in part, by drawing on coping strategies that weigh in broader experiences of physical and social neighbourhood change, and the increasing presence of ethnic minorities in Selwerd.

\subsection{Dealing with Neighbourhood Change}

The increase of students living among the neighbourhood's established residents was interpreted as a negative development. In order to maintain a sense of residential mastery, older adults used a variety of accommodative coping strategies (i.e.,. mind strategies; Golant, 2015).

When the participants talked about neighbourhood change, studentification was often discussed in relation to the increasing presence of ethnic minorities in Selwerd. The increase of people with a non-western background in Selwerd comprises a more recent development. Nowadays, statistics show that Selwerd is the most ethnically diverse neighbourhood in the city of Groningen (in 2011, $22 \%$ of the neighbourhood's population was of a nonwestern background compared to the city's average of 11\%; Onderzoek en Statistiek Groningen, 2018). Claire (female, 81) discussed the influx of immigrants: "There 
were a couple of years in which you could see a moving truck every week. White people moved out and immigrants moved in". Among the majority of our participants there seemed to be anxiety of the 'unknown'; they felt that the new residents had different norms and values to which they could not relate to and they contributed to an increase of crime in the neighbourhood:

I don't hold anything against foreigners, really. They were born somewhere else and they did not ask for that. They have their own religion, that's fine. However, crime, that's the bad thing and we have that in this neighbourhood, that should not be the case. A lot of residents think the same about this issue. (Willy, female, 79)

In light of this, participants rationalised the nuisance and anti-social behaviour of students. This is shown in the following quote by Ellen (female, 76), who attributed vandalism which was probably caused by students, to their "overconfidence":

A couple of times, there were students who scratched cars. We were not happy about that. They were overconfident and were drinking beer. It was clear these were students, because the cars were scratched all the way up to one of the student flats.

It was notable that a number of participants indicated they could relate to students as they used to be young themselves and/or had grandchildren who were studying, which they used as a means to reassess anti-social behaviour. Furthermore, multiple participants expressed the view that students are very reasonable, and it is possible to have a conversation with them in the case of noise-nuisance. Kees (male, 78) and his wife used to live next to a student house, before they moved to a senior apartment:

They always warned us when they had visitors. Well, I think that should not be a problem, right? When you are young you should be able to celebrate your birthday? However, people were leaving the party at 22:00 and then at 24:00 and then at 03:00 and there was a lot of noise. They did not realise we could hear this in our bedroom.... told them that it was noisy. The same day they brought a bouquet of flowers and apologised.

The participants who were living in a senior apartment also experienced noise-nuisance from students, when students would come back from a night out in the city centre. However, possibly because they were not living directly next to students, they were more positive in their appraisal of the nuisance. They felt that students contributed to the liveliness of the neighbourhood and interpreted the noise as something that belongs to city life. As Henk (male, 69) indicates:
I don't have a problem with students. When a group of students comes back from a night out in the city, they are very noisy. But I do not mind, it's something that belongs to city life. It's not a disaster when I can't sleep because of the noise, I can sleep in.

The way in which participants dealt with nuisance experienced from students was in stark contrast to the way in which they talked about and dealt with similar behaviour by ethnic minority residents in their neighbourhood. The feeling of not being able to communicate and the perceived difference in norms and values prevented participants from interacting with them. As the following quote shows, some participants seemed to use resignation as a coping strategy ("it's their culture") in order to deal with the 'newcomers':

In the end, they need a place to stay. But I do not know whether they will adjust to the place. 'Anything goes', that's their culture. And they just close themselves off [from their surroundings]. I can point out the homes of foreigners, everything [their curtains] is closed. (Gerard, male, 74)

The sense of resignation also seemed to apply to the broader experiences of physical and social degradation of the neighbourhood. They were hoping for positive change but did not believe that this would happen soon. Some participants felt that their neighbourhood was neglected by the municipality, because in other post-war neighbourhoods in the city neighbourhood renewal had already commenced. They indicated they did not hold the municipality in high regard, as they felt the housing of students and immigrants was not properly managed. Some participants had visited meetings regarding the plans for the neighbourhood but felt that "the municipality" was not open to their ideas about tackling the challenges of studentification. Hence, the solution to dealing with negative residential experiences seemed to be not to bother. As Willy (female, 79) indicated when she was asked about how she perceived the studentification of Selwerd: “I'm not bothered, you shouldn't get annoyed by anything, otherwise you don't have a life".

\section{Conclusions}

Studentification, which refers to concentrations of students in residential neighbourhoods, can pose challenges for older adults who are ageing-in-place. Older people are to remain living in their own homes and neighbourhoods for as long as possible; benefitting from informal care and support of family, friends and neighbours and the sense of independence and well-being they derive from ageing in familiar surroundings. In this article, we explored the experienced impact of studentification on ageing-in-place for older adults living in an urban neighbourhood in the Netherlands. Our results show how the influx of students in the neighbourhood of Selwerd 
negatively affected older adults' feelings of residential comfort. In line with the body of literature concerning studentification, our participants complained about issues such as noise-nuisance, anti-social behaviour and parking (e.g., Hubbard, 2008; Sage et. al., 2012, 2013; Smith, 2008). Especially for those who were residing in the neighbourhood for several decades, this negatively affected their emotional attachment to the neighbourhood. In spite of this, none of the participants expressed the desire to move. They felt at home in Selwerd, the neighbourhood environment felt familiar to them and they valued the proximity of shops, public transport and health services. To retain a sense of residential mastery, our participants dealt with negative impacts of studentification, at least in part, by drawing on accommodative coping strategies that weigh in broader experiences of physical and social neighbourhood change. In doing so, they rationalised and reassessed their negative experiences resulting from studentification.

This study contributes to understanding the realities of ageing-in-place. One of the underlying assumptions of ageing-in-place policies is that the local social environment will act as a supportive community for their older and more vulnerable residents. Studentification has been associated with a deteriorating community cohesion, which can challenge existing neighbourhood support structures. In the case of this research, the question is whether studentification poses a problem for ageingin-place in terms of challenging neighbourhood support structures. Having a suitable dwelling and the proximity of shops and health services (and if necessary, the help of children and friends/acquaintances) allowed our participants to live independently. The increasing presence of students did not seem to challenge this. However, this might not be the case everywhere, such as in working-class communities in which social contacts often revolve around local family and neighbour networks (see Lager et al., 2013). It should also be noted that studentification might produce (or contribute to) social segregation within the context of a neighbourhood. While the majority of our participants experienced residential comfort in their dwelling, the changes in their wider environment were causing feelings of uncertainty and anxiety, as they were not in control of these changes. As we have shown, how they dealt with these changes differed for the student and immigrant population. There was a relative tolerance of students' anti-social behaviour (see also Munro \& Livingston, 2012) that contrasted with their views on immigrants, whom they associated with an increase in crime in the neighbourhood. For older people, it may be hard to change their dispositions about 'others' compared with younger generations, as they have limited opportunities to encounter difference (Valentine, 2015). Research on the subjective dimensions of ageingin-place would benefit from taking older adults' dispositions about other neighbourhood residents into consideration. Such knowledge could contribute to developing age-friendly interventions in which the focus lies on enhancing mutual respect and understanding, instead of solely focusing on older adults' social integration in the community.

Buffel and Phillipson (2018) have pointed out that in developing age-friendly activity, attention to changes in urban societies is lacking. By discussing studentification in the context of ageing-in-place, we have shown how older adults' subjective experiences of ageing in urban neighbourhoods are interwoven with the ways in which urban societies are changing. At a policy level, the concept of an age-friendly agenda needs to be integrated into urban regeneration schemes, not only in terms of the more tangible elements of the age-friendly model, such as housing and transportation, but also by paying attention to the social elements. This could be done by focusing on creating places in the neighbourhood that are relational in nature: places that are characterised by "overlapping needs, interests, and patterns of behaviour" (Thang \& Kaplan, 2013, p. 228). There are numerous examples of such relational places within the body of literature on intergenerational programs, although they focus on the 'book-end' generations (i.e., children and older adults). In the Netherlands, several initiatives have emerged in recent years which promote intergenerational contact between older adults and students. These initiatives are aimed at decreasing social isolation and loneliness amongst the older population. This includes, for example, a restaurant created by students in Rotterdam called 'Grandma's pop-up' in which older people, under the supervision of a chef, serve traditional Dutch dishes, and several care-homes that offer students rent-free housing for which they, in turn, have to provide the older residents with social and practical support (see Gelmers, 2015; Reed, 2015). As “important actants in the neoliberal city", higher education institutions (HEIs) have the power to remake local communities (Bose, 2015, p. 2616), and hence could play an important role in developing age-friendly initiatives.

In this study, older adults' subjective experiences of ageing-in-place took centre stage. As Hockey, Phillips and Walford (2013, p. 539) argue "the importance of place meanings and attachments for older people's use of space" has found little resonance when it comes to implementing age-friendly policies. Partly, this has to do with the limited extent to which older people are included in decision-making processes about their local environment (Buffel \& Phillipson, 2018; Hockey et al., 2013). Some of our participants felt that the municipality was not open to their ideas about tackling the challenges of studentification in Selwerd, and as a consequence they gave up and decided not to be bothered. It seems to be a missed opportunity not to involve them in this issue, as older residents have much to contribute to urban neighbourhoods' physical, social and cultural revival (Wiesel, 2012). For policymakers and planners, visiting older adults in their own homes and neighbourhoods and listening to their stories could provide valuable information for the practice of place-design. 


\section{Acknowledgments}

The authors would like to thank the respondents for sharing their stories with us. We would also like to thank Linden Douma, Dyon Hoekstra, Jinko Rots and Inge de Vries for the pleasant collaboration in collecting data in Selwerd in 2010. We are particularly grateful for the English language editing that was carried out by David Beynon.

\section{Conflict of Interests}

The authors declare no conflict of interests.

\section{References}

Allinson, J. (2006). Over-educated, over-exuberant and over here? The impact of students on cities. Planning Practice \& Research, 21(1), 79-94.

Baxter, J. (2016). Case studies in qualitative research. In I. Hay (Ed.), Qualitative research methods in human geography (pp. 130-146). Don Mills: Oxford University Press Canada.

Bose, S. (2015). Universities and the redevelopment politics of the neoliberal city. Urban Studies, 52(14), 2616-2632.

Buffel, T., \& Phillipson, C. (2018). A manifesto for the agefriendly movement: Developing a new urban agenda. Journal of Aging \& Social Policy, 30(2), 173-192.

Buffel, T., Phillipson, C., \& Scharf, T. (2013). Experiences of neighbourhood exclusion and inclusion among older people living in deprived inner-city areas in Belgium and England. Ageing \& Society, 33(1), 89-109.

Buffel, T., Verté, D., De Donder, L., De Witte, N., Dury, S., Vanwing, T., \& Bolsenbroek, A. (2012). Theorising the relationship between older people and their immediate social living environment. International Journal of Lifelong Education, 31(1), 13-32.

Droogleever Fortuijn, J., van der Meer, M., Burholt, V., Ferring, D., Quattrini, S., Hallberg, I. R., . . . Wenger, G. C. (2006). The activity patterns of older adults: A cross-sectional study in six European countries. Population, Space and Place, 12(5), 353-369.

Gardner, P. J. (2011). Natural neighborhood networksImportant social networks in the lives of older adults aging in place. Journal of Aging Studies, 25(3), 263-271.

Gelmers, W. (2015). Pop-up restaurant serving grandma's signature dishes. Popupcity. Retrieved from http://popupcity.net/pop-up-restaurantserving-grandmas-signature-dishes

Gemeente Groningen. (2010). Wijkanalyse Selwerd [Neighbourhood analysis Selwerd]. Groningen: Gemeente Groningen.

Golant, S. M. (2015). Aging in the right place. Baltimore, MD: Health Professions Press.

Government of Canada. (2016). Age-friendly communities. Canada.ca. Retrieved from https://www. canada.ca/en/public-health/services/healthpromotion/aging-seniors/friendly-communities. html\#sec3

Hagestad, G. O., \& Uhlenberg, P. (2005). The social separation of old and young: A root of ageism. Journal of Social Issues, 61(2), 343-360.

Hockey, A., Phillips, J., \& Walford, N. (2013). Planning for an ageing society: Voices from the planning profession. Planning Practice \& Research, 28, 527-543.

Hubbard, P. (2008). Regulating the social impacts of studentification: A Loughborough case study. Environment and Planning A, 40(2), 323-341.

Kitchin, R., \& Tate, N. J. (2000). Conducting research into human geography. Harlow: Pearson Education Limited.

Lager, D., Van Hoven, B., \& Huigen, P. P. P. (2013). Dealing with change in old age: Negotiating working-class belonging in a neighbourhood in the process of urban renewal in the Netherlands. Geoforum, 50, 54-61.

Lager, D., Van Hoven, B., \& Huigen, P. P. P. (2015). Understanding older adults' social capital in place: Obstacles to and opportunities for social contacts in the neighbourhood. Geoforum, 59, 87-97.

Lager, D., Van Hoven, B., \& Huigen, P. P. P. (2016). Rhythms, ageing and neighbourhoods. Environment and Planning $A, 48(8), 1565-1580$.

Munro, M., \& Livingston, M. (2012). Student impacts on urban neighbourhoods: Policy approaches, discourses and dilemmas. Urban Studies, 49(8), 1679-1694.

Negrini, C. (2015). Ageing in the city: Geographies of social interactions and everyday life (Unpublished Doctoral dissertation). Kingston University, London.

OECD. (2015). Ageing in cities. Paris: Organisation for Economic Co-operation and Development.

Onderzoek en Statistiek Groningen. (2018). Gronometer. Gronometer. Retrieved from http://groningen. buurtmonitor.nl

Phillipson, C. (2007). The 'elected' and the 'excluded': Sociological perspectives on the experience of place and community in old age. Ageing \& Society, 27(3), 321-342.

Phillipson, C. (2014). Developing age-friendly urban communities: Critical issues for public policy. Public Policy \& Aging Report, 25(1), 4-8.

Reed, C. (2015). Dutch nursing home offers rent-free housing to students. PBS: Public Broadcasting Services. Retrieved from http://www.pbs.org/news hour/rundown/dutch-retirement-home-offers-rentfree-housing-students-one-condition

Rowles, G. D. (1983). Place and personal identity in old age: Observations from Appalachia. Journal of Environmental Psychology, 3(4), 299-313.

Rubinstein, R. L., \& Parmelee, P. A. (1992). Attachment to place and the representation of life course by the elderly. In I. Altman \& S. M. Low (Eds.), Place attachment (pp. 139-1630). New York, NY: Plenum Press.

Sage, J., Smith, D., \& Hubbard, P. (2012). The diverse ge- 
ographies of studentification: Living alongside people not like us. Housing Studies, 27(8), 1057-1078.

Sage, J., Smith, D., \& Hubbard, P. (2013). New-build studentification: A panacea for balanced communities? Urban Studies, 50(13), 2623-2641.

Smith, A. E. (2009). Ageing in urban neighbourhoods. Place attachment and social exclusion. Bristol: The Policy Press.

Smith, D. P. (2006). 'Studentification'. A guide to opportunities, challenges and practice. London: Universities UK.

Smith, D. P. (2008). The politics of studentification and '(un)balanced' urban populations: Lessons for gentrification and sustainable communities? Urban Studies, 45(12), 2541-2564.

Thang, L. L., \& Kaplan, M. S. (2013). Intergenerational pathways for building relational spaces and places. In G. D. Rowles \& M. Bernard (Eds.), Environmental gerontology. Making meaningful places in old age (pp. 225-252). New York, NY: Springer Publishing Company.

Valentine, G. (2015). Intergenerationality and prejudice. In R. M. Vanderbeck \& N. Worth (Eds.), Intergenerational Space (pp. 155-168). Oxon: Routledge.

Van der Meer, M., Droogleever Fortuijn, J., \& Thissen, F. (2008). Vulnerability and environmental stress of older adults in deprived neighbourhoods in the Netherlands. Tijdschrift voor economische en sociale geografie, 99(1), 53-64.

Wiesel, I. (2012). Can ageing improve neighbourhoods? Revisiting neighbourhood life-cycle theory. Housing, Theory and Society, 29(2), 145-156.

Wiles, J. L., Leibing, A., Guberman, N., Reeve, J., \& Allen, R. E. S. (2012). The meaning of "aging in place" to older people. The Gerontologist, 52(3), 357-366.

World Health Organization. (2007). Global age-friendly cities: A guide. Geneva: World Health Organization.

\section{About the Authors}

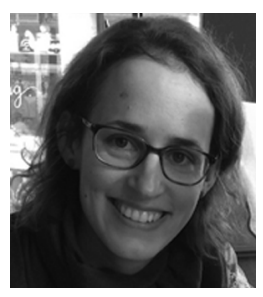

Debbie Lager is a Cultural Geographer. Her research interests include the subjective dimensions of ageing-in-place and ageing in urban neighbourhoods. She has extensive experience in qualitative methodologies and has used several methods, such as photovoice and walking interviews to understand how older adults experience and make use of neighbourhood space. She is currently working as a lecturer in Social Work at the Hanze University of Applied Sciences.

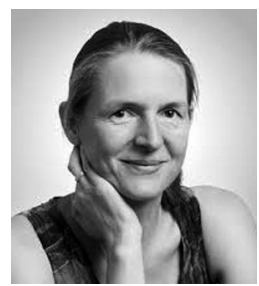

Bettina van Hoven is Associate Professor of Cultural Geography and Academic Director of Education at the University College Groningen, the Netherlands. Her recent research has concentrated on the feelings of belonging and the attachment of various population groups to the place where they live. In the past, she has worked on projects involving women in Eastern Europe, diaspora and migration, institutions, ethnicity, sexuality, disabilities, youth and nature. 